\title{
Efeito da incorporação de folhas de oliveira (Olea europaea L.) no desenvolvimento e qualidade da carne de frangos
}

\author{
Effect of incorporating olive leaves (Olea europaea L.) on the \\ development and quality of poultry meat
}

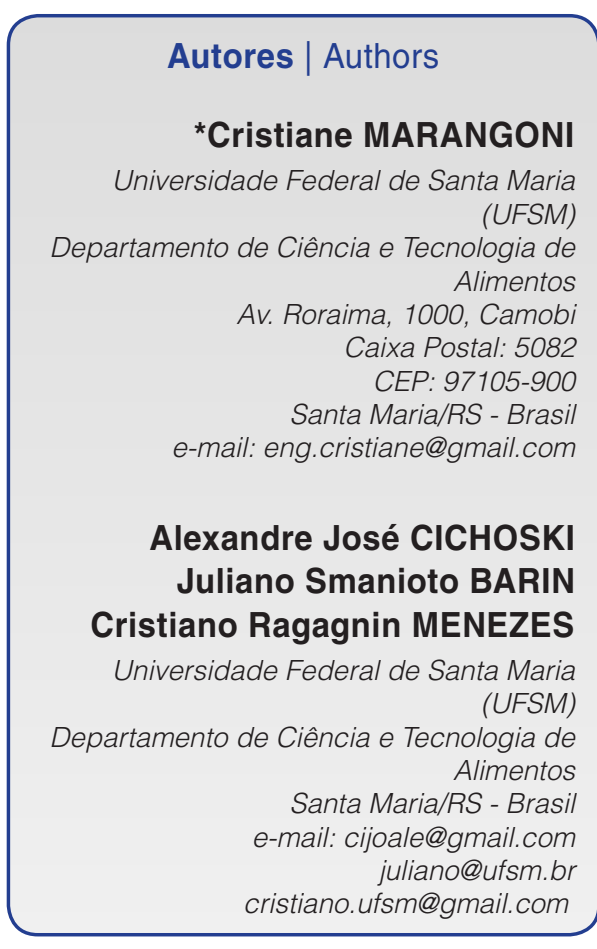

*Autor Correspondente / Corresponding Author

Recebido: Abr. 10, 2015

Aprovado: Nov. 11, 2015

\section{Resumo}

Foi realizada suplementação de folhas de oliveira na ração de frangos na quantidade de 5 e $10 \mathrm{~g}$ de folhas/kg de ração e acompanhou-se o desempenho dos animais durante seu crescimento. Depois do abate, as coxas e sobrecoxas foram coletadas e armazenadas a $4{ }^{\circ} \mathrm{C}\left( \pm 1^{\circ} \mathrm{C}\right)$ por 12 dias. Os resultados mostraram melhor conversão alimentar dos frangos que receberam dieta suplementada com $5 \mathrm{~g} / \mathrm{kg}$. As coxas e sobrecoxas dos frangos que receberam folhas de oliveira apresentaram melhor estabilidade microbiológica que o controle, em que $5 \mathrm{~g} / \mathrm{kg}$ inibiu o crescimento de Staphylococcus aureus, aeróbios psicrotróficos e mesófilos e $10 \mathrm{~g} / \mathrm{kg}$ inibiu o crescimento de Enterococcus spp., bactérias ácido láticas, coliformes termotolerantes e totais, Pseudomonas, Clostridium perfringens e Escherichia coli $(p<0,05)$. Os resultados indicam a possibilidade de uso de folhas de oliveira, como suplemento alimentar, com vistas à melhoria da qualidade microbiológica da carne de frango.

Palavras-chave: Folhas de oliveira; Frangos; Bactérias.

\section{Summary}

Supplementation of broiler feed with olive leaves was carried out at the rate of 5 and $10 \mathrm{~g}$ of leaves $/ \mathrm{kg}$ feed and the performance of the animals monitored during their growth. After slaughter, the thighs and drumsticks were stored at $4{ }^{\circ} \mathrm{C}$ $\left( \pm 1^{\circ} \mathrm{C}\right)$ for 12 days. The results showed better feed conversion by the chickens fed the feed supplemented with $5 \mathrm{~g} / \mathrm{kg}$. The thighs and drumsticks of chickens that received the feed supplemented with olive leaves showed better microbiological stability than the control treatment, $5 \mathrm{~g} / \mathrm{kg}$ inhibiting the growth of Staphylococcus aureus, psychrotrophic and mesophilic aerobes and $10 \mathrm{~g} / \mathrm{kg}$ inhibiting the growth of Enterococcus spp, lactic acid bacteria, coliforms, Pseudomonas, Clostridium perfringens and Escherichia coli $(p<0.05)$. The results indicated the possibility of using olive leaves as a food supplement aimed at improving the microbiological quality of chicken meat.

Key words: Olive leaves; Chicken; Bacteria. 


\section{Introdução}

A carne de frango pode veicular patógenos como Salmonella spp, Staphylococcus aureus, Campylobacter spp., Listeria spp., Escherichia coliO157:H7, Shigella spp. e Yersinia spp., possíveis causadores de danos à saúde e toxinfecções alimentares, além de micro-organismos associados à deterioração, como Pseudomonas, que são responsáveis por consideráveis perdas econômicas nas indústrias processadoras de carne e produtos derivados. (OLIVEIRA et al., 2009; OLIVEIRA et al., 2004; DELAZARI, 2003).

A suplementação de antimicrobianos na dieta de animais em crescimento tem despontado como uma alternativa a minimizar o crescimento microbiano, sem oferecer risco para a saúde dos consumidores, além de proporcionar matéria-prima com melhor qualidade (NASCIMENTO, 2013; VILLA; OLIVEIRA, 2012). A oliveira (Olea europaea L.), planta frutífera da família botânica Oleaceae, que começou a ser cultivada no Brasil em 1800, possui propriedades antimicrobianas atribuídas aos seus compostos fenólicos, particularmente o hidroxitirosol e a oleuropeína (PEREIRA et al., 2007). Sudjana et al. (2009) demonstraram atividade antimicrobiana das folhas de Olea europaea L. frente a Campylobacter jejuni, Helicobacter pylori e Staphylococcus aureus. Outros ensaios demonstraram que extratos das folhas de oliveira apresentam atividade antioxidante, anti-inflamatória, antimicrobiana e antiviral (BOCK et al., 2013; KONTOGIANNI; GEROTHANASSIS, 2012; KOMAKI et al., 2003; LEE-HUANG et al., 2003), propriedades atribuídas à composição rica em compostos fenólicos.

Bisignano et al. (1999) avaliaram a atividade antimicrobiana in vitro da oleuropeína e do hidroxitirosol extraídos de folhas de oliveira e identificaram eficiência diante de Staphylococcus aureus. Em outro estudo, Bisignano et al. (2001) identificaram componentes antimicrobianos das folhas da oliveira e constataram a eficácia dos aldeídos alifáticos de cadeia longa diante de bactérias gram-positivas e gram-negativas.

Ao investigar a atividade in vitro de um extrato comercial de folhas de oliveira (Olea europaea L.) que continha $4,4 \mathrm{mg} / \mathrm{mL}$ de oleuropeína, diante de uma vasta gama de micro-organismos, Sudjana et al. (2009) constataram que o composto apresentou atividade inibitória para Helicobacter pylori, Campylobacter jejuni, e Staphylococcus aureus. A atividade antimicrobiana in vitro de folhas de oliveira também foi estudada por Markin, Duek e Berdicevsky (2003) que observaram eficácia especialmente em Klebsiela e Pseudomonas.

O Brasil está entre os três maiores produtores mundiais de carne de frango e, desde 2004, ocupa a posição de maior exportador mundial fornecendo para mais de 150 países (UBABEF, 2012). Segundo relatório anual da Ubabef (2012), a região sul do Brasil é responsável por $61,53 \%$ do volume de frango produzido, cujo principal destino é o Oriente Médio, na forma de cortes, frango inteiro, frango industrializado e outros produtos. Porém, esta carne em condições não adequadas de processamento e armazenamento pode se tornar veículo de transmissão de inúmeros micro-organismos, alguns deles patógenos ao homem. Considerando que as toxinfecções alimentares de origem microbiana têm sido reconhecidas como um problema de saúde pública abrangente e causa importante na diminuição da produtividade e perdas econômicas que afetam países, empresas e consumidores (NASCIMENTO, 2011), realizou-se o acompanhamento do desempenho de frangos que receberam em suas dietas folhas de oliveira como suplemento e, posteriormente, avaliou-se a evolução de diferentes bactérias nas coxas e sobrecoxas durante seu armazenamento por 12 dias a $4^{\circ} \mathrm{C}\left( \pm 1^{\circ} \mathrm{C}\right)$.

\section{Material e métodos}

Folhas de Oliveira (Olea europaea L.) da variedade Ascolana foram colhidas na EPAGRI (Empresa de Pesquisa Agropecuária e Extensão Rural de Santa Catarina) de uma plantação de Oliveiras de 5 anos, entre os meses de janeiro e março de 2012. Foram removidos os possíveis contaminantes físicos e, posteriormente, realizou-se secagem em estufa a $45^{\circ} \mathrm{C}$ com circulação de ar por 72 horas. Em seguida, o material seco foi moído em moinho de navalhas do tipo Willey com peneiras de $1 \mathrm{~mm}$. As folhas moídas foram analisadas em relação ao conteúdo de umidade, proteína, resíduo mineral fixo e gordura, de acordo com metodologias descritas em Brasil (1999).

\subsection{Animais e dieta}

No estudo, foram utilizados 2.520 frangos de corte linhagem Cobb, alojados em agroindústria do oeste de Santa Catarina (SC), Brasil. A unidade experimental foi composta por dois galpões de $20 \mathrm{~m}$ de comprimento $\times 7 \mathrm{~m}$ de largura. Cada galpão, possuía 18 boxes medindo $3 \mathrm{~m}$ de comprimento $\times 2 \mathrm{~m}$ de largura, com capacidade para alojar até 70 frangos por box. Os frangos foram distribuídos ao acaso nos 36 boxes em condições de aviário normal (ambiente, manejo, bem-estar), contendo campânula a gás, comedouro tubular, bebedouro pendular, ração e água à vontade, resultando em 70 aves/box com um total de três tratamentos com doze repetições (6 em cada galpão), totalizando 3 grupos de 840 frangos cada. Um grupo serviu de controle e foi alimentado com dieta tradicional (T1), enquanto os outros dois grupos foram alimentados com dietas suplementadas com folhas de oliveira nas quantidades de $5 \mathrm{~g} / \mathrm{kg}$ de ração (T2) e de $10 \mathrm{~g} / \mathrm{kg}$ de ração (T3). Durante os 42 dias de crescimento, foi acompanhado o desempenho dos 
animais. Aos 42 dias, realizou-se o abate dos animais e coletaram-se as coxas e sobrecoxas com ossos e com pele para armazenamento a $4^{\circ} \mathrm{C}\left( \pm 1^{\circ} \mathrm{C}\right)$ durante 12 dias para acompanhamento da evolução da flora microbiana.

\subsection{Avaliação do desempenho}

Para avaliação do desempenho dos frangos, foram analisados: PI (peso Inicial), PF (Peso Final), CRT (Consumo de Ração Total), CRD (Consumo Ração Diário), GP (Ganho de Peso), GPD (Ganho de Peso Diário), CA (Conversão Alimentar) e TM (Taxa de Mortalidade).

\subsection{Análises microbiológicas}

As coxas e sobrecoxas dos três tratamentos foram analisadas nos dias 0 (zero), 3, 6, 9 e 12, quanto à evolução das contagens dos seguintes microrganismos:

Clostridium perfringens: a análise foi realizada com meio de cultura TSC e semeadura Pour Plate de profundidade e leitura após $24 \mathrm{~h}$ de incubação a $36^{\circ} \mathrm{C}$ $\left( \pm 1^{\circ} \mathrm{C}\right)$, conforme metodologia descrita pela IN 62 de 26 de agosto de 2003 do Ministério da Agricultura (BRASIL, 2003).

Coliformes Termotolerantes: foi realizada por Petrifilm CC, com semeadura de superfície e leitura após $24 \mathrm{~h}$ de incubação a $44{ }^{\circ} \mathrm{C}\left( \pm 1^{\circ} \mathrm{C}\right)$, de acordo com Método AOAC 991; Staphylococcus aureus: foi realizada por Petrifilm STX, com semeadura de superfície e leitura após $24 \mathrm{~h}$ de incubação a $36{ }^{\circ} \mathrm{C}\left( \pm 1^{\circ} \mathrm{C}\right)$, de acordo com Método AOAC 2003.07; Mesófilos: foi realizada por Petrifilm $A C$ por semeadura de superfície e incubação à temperatura de $48{ }^{\circ} \mathrm{C}$ a $35^{\circ} \mathrm{C}\left( \pm 1^{\circ} \mathrm{C}\right)$ e posterior leitura, de acordo com Método AOAC 990.12; Escherichia coli: foi realizada por Petrifilm EC através de semeadura de superfície, realizando-se leitura após incubação por $48 \mathrm{~h}$ a $35^{\circ} \mathrm{C}\left( \pm 1^{\circ} \mathrm{C}\right)$, de acordo com Método AOAC Official Method 998.08 e 991.14; Enterococcus spp.: foi realizada por Petrifilm EB através de semeadura de superfície e realizou-se leitura após incubação por $24 \mathrm{~h}$ a $37^{\circ} \mathrm{C}\left( \pm 1^{\circ} \mathrm{C}\right)$ de acordo com Método AOAC 2003.01; Coliformes totais: foi realizada de acordo com Método AOAC 998.08 e 991.14 (HORWITZ, 2003).

Aeróbios Psicrotróficos: foi realizada por PCA por meio de semeadura de superfície e incubação por 10 dias a $7^{\circ} \mathrm{C}\left( \pm 1^{\circ} \mathrm{C}\right)$ e posterior leitura, de acordo com Salfinger e Tortorello (2001).

Bactérias Láticas: foi realizada com meio MRS por semeadura Pour Plate de profundidade entre 48 e $72 \mathrm{~h}$ a $30{ }^{\circ} \mathrm{C}\left( \pm 1{ }^{\circ} \mathrm{C}\right)$, conforme metodologia descrita pelo Brasil (2003).

Pseudomonas: foi realizada com meio CFC por de semeadura de superfície após incubação por $44 \mathrm{~h}$ a $25^{\circ} \mathrm{C}$ $\left( \pm 1^{\circ} \mathrm{C}\right)$, conforme metodologia do ISO (2010).
Shigella, Streptococcus, Klebsiela e Yersinia foram determinadas por tipificação em Vitek2 (BRASIL, 2003).

Campylobacter (jejuni, coli, lari) foi determinada pelo método Bax (VIDAS ${ }^{\circledR}$ Campylobacter [CAM] Referência 30111/DUPONT. BAX System UserGuide. USA Dupont QualiconInc, 2000-2005).

Salmonella foi determinada pelo método AOAC 2011.03 (VIDAS ${ }^{\circledR}$ Salmonella [SLM] Assay) e Listeria monocytogenes foi determinada pelo método AOAC 2004.02 (VIDAS $^{\circledR}$ [LIS] Assay) (HORWITZ, 2003).

\subsection{Análise estatística}

Os resultados foram obtidos em triplicata e submetidos à análise de variância (ANOVA), utilizando o delineamento de blocos inteiramente casualizados. As médias foram comparadas pelo teste de Tukey, ao nível de $5 \%$ de probabilidade de erro, através do programa Statistica - Stat Soft versão 7.

\section{Resultados e discussão}

As folhas de oliveira da variedade Ascolano secas e moídas apresentaram em base seca $4,65 \%$ de umidade, 4,69\% de resíduo mineral fixo, 1,38\% de lipídeos, 23,3\% de fibra bruta e 12,73 g/100 g NT × 6,25 de proteína bruta. Em estudo realizado por Botsoglou et al. (2010), folhas de oliveira foram secas a $45^{\circ} \mathrm{C}$ durante 3 dias consecutivos e moídas em peneira de $2 \mathrm{~mm}$. Depois da análise, indicaram resultados em base seca próximos aos encontrados neste estudo para os parâmetros de umidade e resíduo mineral fixo, sendo $5,0 \%$ e $5,4 \%$, respectivamente. A umidade encontrada neste estudo de $4,65 \%$ garante boa qualidade às folhas secas, uma vez que esse teor não é favorável ao desenvolvimento de fungos, bolores e leveduras.

A Tabela 1 apresenta a matriz nutricional que compreende a base da alimentação dos frangos. À esta matriz foi realizada adição das folhas de oliveira e realizada avaliação do desempenho dos animais e, posteriormente, da carne.

A Tabela 2 apresenta o desempenho dos frangos pertencentes aos três tratamentos durante os 42 dias que receberam ração. Constatou-se que, no início do experimento os frangos pertencentes aos três tratamentos apresentaram o mesmo peso inicial $(\mathrm{PI})$ e, no $42^{\circ}$ dia, quando foram abatidos, os frangos dos tratamentos T1 e T3 apresentaram maior peso final (PF), em relação aos frangos pertencentes ao tratamento T2. Este resultado pode ter sido influenciado pela quantidade de consumo de ração total (CRT), uma vez que ocorreu maior consumo de ração nos tratamentos T1 e T3 (Tabela 2).

A partir do consumo de ração total (CRT) e do ganho de peso (GP) dos frangos foi obtida a conversão alimentar (CA). Para este parâmetro, os frangos 
que receberam dieta suplementada com folhas de oliveira na quantidade de $5 \mathrm{~g} / \mathrm{kg}$ (T2) apresentaram os melhores valores, diferindo significativamente dos frangos pertencentes ao T3. Para os frangos que receberam dieta com folhas de oliveira na quantidade de $10 \mathrm{~g} / \mathrm{kg}$ (T3) não foi registrada mortalidade (TM) durante o acompanhamento, diferenciando significativamente $(p<0,05)$ dos tratamentos T1 e T2. Folhas de oliveira foram usadas na dieta de codornas e promoveram melhoria significativa na produção de ovos em relação ao tratamento controle, mas não demonstraram

Tabela 1. Matriz nutricional referente à ração elaborada para alimentação dos frangos.

\begin{tabular}{lr} 
& Quantidade (g) \\
Milho & 558,00 \\
Farelo de soja & 315,34 \\
Farinha de vísceras de aves & 68,00 \\
Farinha de penas & $0,0-0,0$ \\
Óleo de soja & 28,00 \\
Gordura de aves & 0,00 \\
Calcário calcítico & 7,50 \\
Sal granulado iodado & 4,40 \\
L-Lisina HCL 50\% & 6,70 \\
Metionina MHA & 4,60 \\
Cloreto colina 75\% & 0,45 \\
Aditivo antimicotoxinas & 2,00 \\
L-Treonina & 2,07 \\
Rovabio Excel AP xilase + B-glucanase & 0,05 \\
Ronozyme ProAct - protease & 0,20 \\
Etoxiquine & 0,15 \\
Ronozyme HiPhos (M) fitase & 0,02 \\
Lincomicina 44\% & 0,01 \\
Anticoxilidiano & 0,50 \\
Premix * & 2,00 \\
\hline Premix: Conposto por vitama
\end{tabular}

*Premix: Composto por vitamina $\mathrm{A}(4.275 \mathrm{KUI})$, vitamina $\mathrm{D}_{3}$ (1.395 KUI), vitamina $\mathrm{E}(22.500 \mathrm{mg})$, vitamina $\mathrm{K}_{3}(1.350 \mathrm{mg})$, vitamina $\mathrm{B}_{1}^{3}(1.350 \mathrm{mg})$, vitamina $B_{2}(3.600 \mathrm{mg})$, vitamina $B_{6}^{3}(1.800 \mathrm{mg})$, vitamina $\mathrm{B}_{1}(9.900 \mu \mathrm{g})$, ácido pantotênico $(9.000 \mathrm{mg})$, niacina $(18.000 \mathrm{mg})$, ácido fólico $(900 \mathrm{mg})$, biotina $(76.500 \mu \mathrm{g})$, cobre $(7.200 \mathrm{mg})$, ferro $(27.000 \mathrm{mg})$, manganês $(27.000 \mathrm{mg})$, iodo $(450 \mathrm{mg})$, zinco $(45.000 \mathrm{mg})$ e selênio $(180 \mathrm{mg})$. diferença na taxa de mortalidade em relação ao controle (CHRISTAKI et al., 2011). Os benefícios do uso das folhas de oliveira foram atribuídos à presença de polifenóis e oleuropeína, conforme já indicado por Malik e Bradford (2008).

O acompanhamento zootécnico realizado durante os 42 dias, demonstrou que os frangos que receberam $10 \mathrm{~g}$ de folhas de oliveiras/kg de ração (T3) em suas dietas apresentaram melhor desempenho do que os frangos do tratamento controle, para o parâmetro TM, e desempenho equivalente a T2 para os demais parâmetros avaliados.

No presente estudo, foi verificada CA significativamente melhor pelo tratamento que recebeu $5 \mathrm{~g}$ de folhas de oliveira/kg de ração enquanto os animais que receberam $10 \mathrm{~g}$ de folhas de oliveira/kg de ração registraram a mesma CA que o controle. Embora o peso final dos animais não tenha sido maior para ambos os tratamentos que receberam folhas de oliveira em relação ao controle, o desempenho dos animais não foi afetado negativamente, o que pode ser constatado pela $\mathrm{TM}$, que foi menor para os tratamentos que receberam folhas de oliveira na dieta. Os resultados positivos para o desempenho zootécnico dos frangos alimentados com folhas de oliveira em relação aos que receberam dieta convencional indica que as folhas de oliveira podem constituir uma alternativa para a alimentação de frangos de corte. Como neste estudo, Erener et al. (2009) relataram que a suplementação de dietas de frangos com extratos de folhas de oliveira proporcionou um aumento no peso corporal e melhoria na taxa de conversão alimentar dos animais. Em estudo realizado em codornas japonesas, Christaki et al. (2011) relataram que as folhas de oliveira não tiveram efeito significativo no consumo de ração ou na taxa de conversão alimentar, no entanto, os grupos que receberam ração suplementada com folhas de oliveira tiveram um consumo de ração relativamente maior que o grupo controle, assemelhando-se ao maior resultado de CRT verificado para T3 neste estudo. Cayan e Erener (2015) avaliaram o efeito de folhas de oliveira sobre o desempenho durante crescimento de galinhas poedeiras

Tabela 2. Desempenho dos frangos pertencentes aos três tratamentos durante os 42 dias que receberam a ração.

\begin{tabular}{|c|c|c|c|c|c|c|c|c|}
\hline \multicolumn{9}{|c|}{ Desempenho Zootécnico } \\
\hline & $\mathrm{PI}(\mathrm{g})$ & PF (g) & CRT (g) & CRD (g) & GP (g) & GPD (g) & $\mathrm{CA}^{*}$ & TM (\%) \\
\hline \multirow[t]{2}{*}{$\mathrm{T} 1$} & $46,0^{a}$ & $2773,2^{a}$ & $4304,3^{a}$ & $100,1^{a}$ & $2727,1^{a}$ & $63,4^{a}$ & $1,58^{a}$ & $0,24^{a}$ \\
\hline & $(0,00)$ & $(0,00)$ & $(0,00)$ & $(0,51)$ & $(0,00)$ & $(0,00)$ & $(0,00)$ & $(0,00)$ \\
\hline \multirow[t]{2}{*}{$\mathrm{T} 2$} & $46,0^{a}$ & $2756,2^{b}$ & $4271,5^{b}$ & $99,3^{b}$ & $2710,2^{b}$ & $63,1^{b}$ & $1,57^{b}$ & $0,12^{a}$ \\
\hline & $(0,00)$ & $(0,010)$ & $(0,10)$ & $(0,00)$ & $(0,00)$ & $(0,00)$ & $(0,00)$ & $(0,00)$ \\
\hline \multirow[t]{2}{*}{ T3 } & $46,0^{a}$ & $2799,1^{a}$ & $4343,9^{a}$ & $101,0^{a}$ & $2753,1^{a}$ & $64,0^{a}$ & $1,58^{a}$ & $0,0^{b}$ \\
\hline & $(0,00)$ & $(0,00)$ & $(0,00)$ & $(0,00)$ & $(0,00)$ & $(0,00)$ & $(0,00)$ & $(0,00)$ \\
\hline
\end{tabular}

Nota 1: a,b,c são analisadas na vertical. Letras diferentes apresentam diferença significativa $(P<0,05)$ pelo teste de Tukey. $O$ desvio padrão encontra-se entre parênteses. Nota 2: (T1) dieta controle, (T2) dieta suplementada com $5 \mathrm{~g}$ oliveira/kg de ração, (T3) dieta suplementada com 10g oliveira/kg de ração. Nota 3: PI (peso Inicial), PF (Peso Final), CRT (Consumo de Ração Total), CRD (Consumo Ração Diário), GP (Ganho de Peso), GPD (Ganho de Peso Diário), CA (Conversão Alimentar), TM (Taxa de Mortalidade). * Consumo de ração em um determinado tempo/ganho de peso. 
Efeito da incorporação de folhas de oliveira (Olea europaea L.) no desenvolvimento e qualidade da carne de frangos MARANGONI, C. et al.

e não verificaram influência sobre o consumo de ração e conversão alimentar, mas registraram aumento do peso corporal dos animais em relação ao controle, resultado semelhante ao encontrado para GP de T3 neste estudo.

A segurança e qualidade dos alimentos como a carne in natura de frango pode ser estimada pela contagem de micro-organismos indicadores como aeróbios mesófilos e psicrotróficos (JAY, 2005). Na Figura 1, é apresentado o número de colônias $\left(\log _{10}\right.$ UFC/g) de aeróbias mesófilas (AM), bactérias ácido láticas (BAL), aeróbias psicrotróficas (AP) e Pseudomonas $(\mathrm{CP})$.

A contagem de aeróbios mesófilos de $10^{7} \mathrm{UFC} / \mathrm{g}$ ou $7 \log _{10}$ UFC/g é estabelecida por ICMSF (1986) como indicador para o fim da vida útil da carne de frango resfriada. Alguns estudos são mais criteriosos considerando fora das condições higiênico sanitárias ideais os frangos que ultrapassam $10^{6} \mathrm{UFC/g}$ (RITTER; BERGMANN, 2003). Pela Figura 1-AM, verifica-se que os tratamentos que receberam dieta suplementada com folhas de oliveiras (T2 e T3) atingiram contagens máximas de 5,63 e 5,87 $\log _{10}$ UFC/g, respectivamente, enquanto o tratamento controle apresentou contagens de 6,07 $\log _{10}$ UFC/g a partir do $3^{\circ}$ dia de armazenamento. Em todos os dias analisados, o número de colônias de bactérias mesófilas dos tratamentos T2 e T3 foi menor comparado ao encontrado no tratamento controle. Em virtude de a contagem de aeróbios mesófilos estimarem a população microbiana total e elevadas contagens indicarem baixa qualidade e reduzida vida de prateleira do alimento (JAY, 2005; GILL, 1998), pode-se dizer que as folhas de oliveira adicionadas na dieta de frangos proporcionaram melhor estabilidade da carne e um aumento da vida de prateleira das coxas e sobrecoxas armazenadas a $4^{\circ} \mathrm{C}$, em relação ao tratamento que recebeu a dieta convencional.

O número de colônias de bactérias láticas nos tratamentos com folhas de oliveiras (T2 de 1,64 a 4,49 $\log _{10}$ UFC/g e T3 de 1,50 a 3,77 $\log _{10}$ UFC/g) em
AM

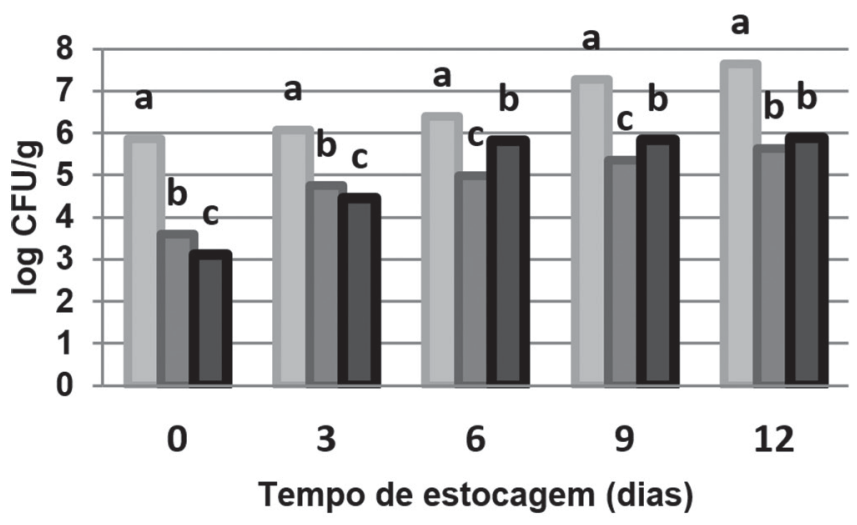

DT1 - Controle DT2 - 5g Oliveira DT3 - $10 \mathrm{~g}$ Oliveira

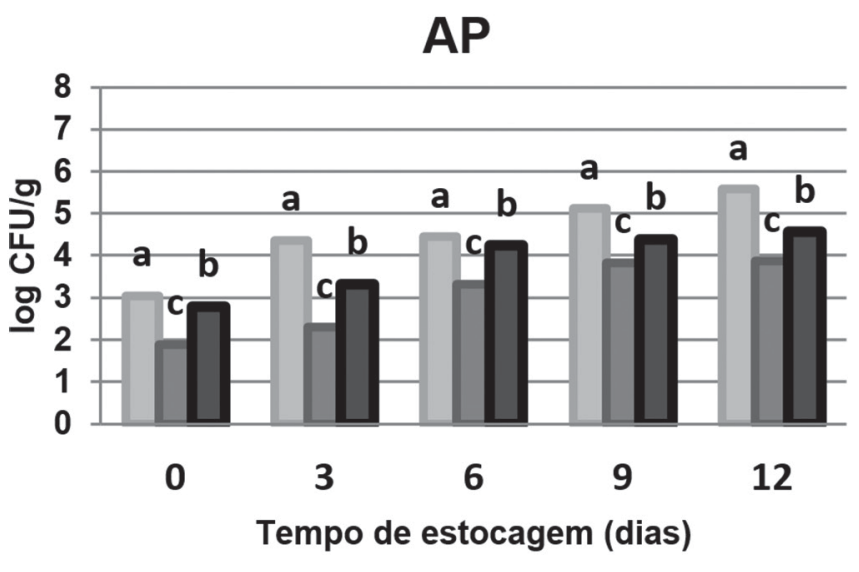

T1 - Controle DT2 - $5 \mathrm{~g}$ Oliveira DT3 - $10 \mathrm{~g}$ Oliveira

\section{BAL}

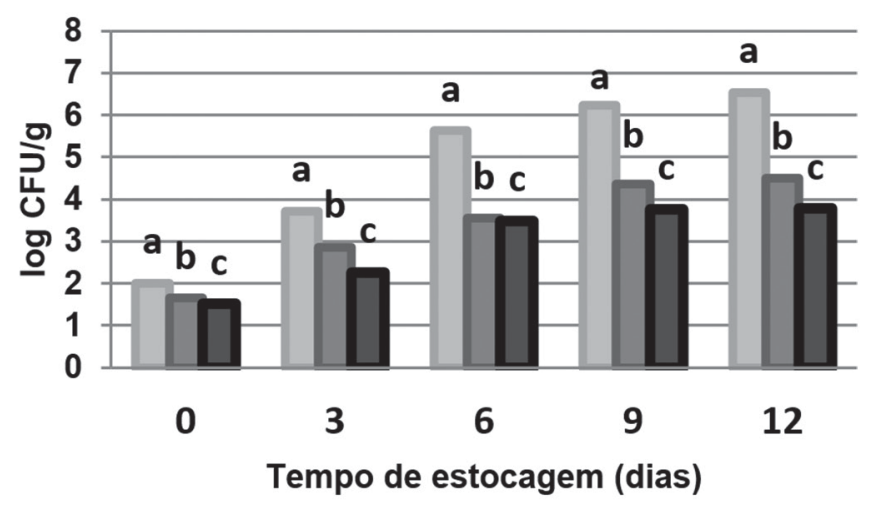

T1 - Controle DT2 - 5g Oliveira DT3 - $10 \mathrm{~g}$ Oliveira

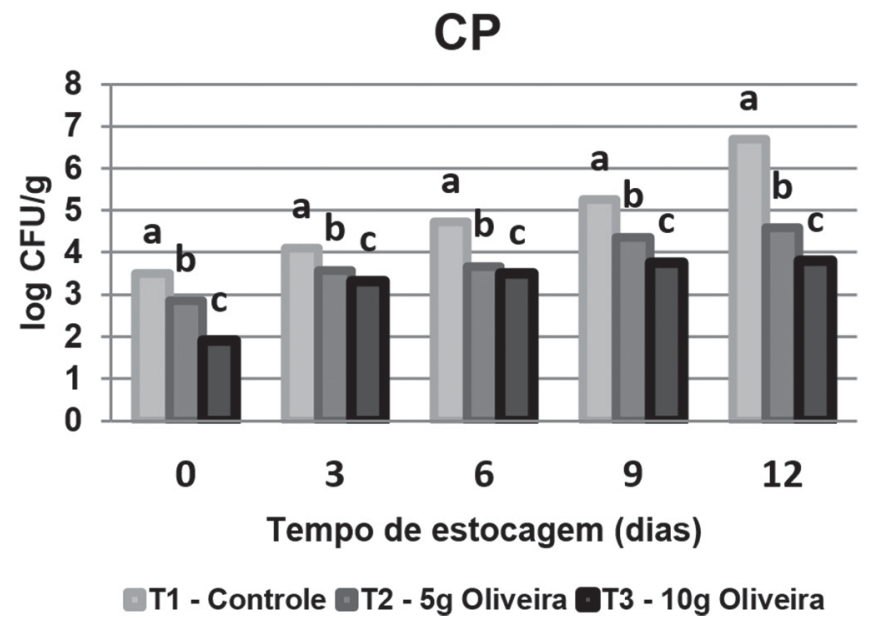

Figura 1. Número de colônias $\left(\log _{10} \mathrm{UFC} / g\right)$ de aeróbias mesófilas (AM); bactérias ácido láticas (BAL); aeróbias psicrotróficas (AP) e Pseudomonas (CP), em coxas e sobrecoxas de frangos armazenadas a $4{ }^{\circ} \mathrm{C}$ por 12 dias; a,b,c são analisadas entre T1, T2 e T3 por intervalo de análise. Letras diferentes apresentam diferença significativa $(P<0,05)$ pelo teste de Tukey. 
todos os dias analisados foi menor do que o encontrado no tratamento controle (T1 de 2,00 a 6,54 $\log _{10} \mathrm{UFC/g}$ ) e diferiram significativamente $(p<0,05)$ entre si. Esses resultados demonstram que as folhas de oliveiras, quando administradas via dieta, apresentam efeito nas bactérias láticas (Figura 1, BAL). Entre os tratamentos com folhas de oliveiras, T3 (10g de folhas de oliveira/kg de ração) apresentou, durante os 12 dias, menor número de colônias de bactérias láticas, diferindo estatisticamente $(p<0,05)$ de T2 ( $5 \mathrm{~g}$ de folhas de oliveira/kg de razão). Este resultado pode ser devido à oleuropeína, principal componente das folhas de oliveira e indicada como positiva na ação contra bactérias ácido láticas (RUIZ-BARBA et al., 1990), estar presente em maior percentual em T3. Botsoglou et al. (2010) adicionaram 5 e $10 \mathrm{~g}$ de folhas de oliveira/kg na ração de perus e avaliaram o crescimento microbiano nos filés de peito armazenados a $4{ }^{\circ} \mathrm{C}$ por 12 dias. No $12^{\circ}$ dia de armazenamento, o número de bactérias láticas no tratamento controle foi de $6,5 \log _{10}$ UFC/g e nos tratamentos com 10 e $5 \mathrm{~g}$ de folhas de oliveiras foram de 4 e $5 \log _{10}$ UFC/g, respectivamente. Neste estudo, o número de bactérias lácticas nas coxas e sobrecoxas de frangos no $12^{\circ}$ dia foram de 3,77 e $4,49 \log _{10}$ UFC/g para os tratamentos $\mathrm{T} 3 \mathrm{e} \mathrm{T} 2$, respectivamente, sendo esses valores menores do que os encontrados por Botsoglou et al. (2010) no mesmo tempo de armazenamento e na mesma temperatura.

De acordo com ICMSF (1986), que estabelece $10^{6}$ a $10^{7}$ UFC/g como padrão de deterioração de carne refrigerada, as coxas e sobrecoxas se mantiveram adequadas para consumo em relação aos psicrotróficos (Figura 1-AP) durante os 12 dias. Os tratamentos que receberam folhas de oliveira apresentaram redução significativa $(p<0,05)$ na contagem deste micro-organismo em relação ao tratamento controle. Resultados semelhantes de redução de bactérias psicotróficas foram encontrados por Botsoglou et al. (2010), ao avaliar o efeito de folhas de oliveira em filés de peru, encontrando número de colônias de 4,6 e $5,7 \log _{10}$ UFC/g nos tratamentos que receberam 10 e $5 \mathrm{~g}$ de folhas de oliveira/kg de ração, sendo esses valores maiores do que os encontrados neste estudo, que foram de 4,55 para T3 e 3,87 $\log _{10}$ UFC/g para T2 (Figura 1-AP).

Ao avaliar o efeito antimicrobiano de folhas de oliveira em comparação ao alecrim suplementados via dieta de perus, Govaris et al. (2010) verificaram capacidade antimicrobiana significativamente superior das folhas de oliveira ante o alecrim e ao tratamento controle para todas as bactérias avaliadas (Enterobacterias, ácido láticas, psicotróficas e contagem total) na carne de peito refrigerada a $4{ }^{\circ} \mathrm{C}$ por 12 dias. Estes resultados foram semelhantes aos encontrados neste estudo com carne de frango nas mesmas condições de temperatura e tempo de estocagem, em que foi constatada capacidade antimicrobiana das folhas de oliveira em bactérias patógenas e deteriorantes (Enterococcus spp., bactérias ácido láticas, coliformes termotolerantes e totais, Pseudomonas, Clostridium perfringens, Escherichia coli, Staphylococcus aureus, aeróbios psicrotróficos e mesófilos) (Figuras 1 e 2).

A análise de Aeróbios totais e Pseudomonas spp. também são indicadores de deterioração de carne de frangos (DOMINGUEZ; SCHAFFNER, 2007). A contagem de Pseudomonas spp. é definida por vários autores como indicativa de término de vida útil quando atinge valores de 6 a $7 \log _{10}$ UFC/g (ALLEN et al., 1997; MEHYAR, 2005). Considerando os valores de CP apresentados na Figura 1, os três tratamentos mantiveram-se apropriados para consumo até os 12 dias de armazenamento a $4{ }^{\circ} \mathrm{C}$. Os tratamentos que receberam folhas de oliveira (T2 e T3) apresentaram número de colônias de Pseudomonas significativamente menores $(p<0,05)$ do que o controle (T1) em todos os dias de armazenamento, sendo que o uso de $10 \mathrm{~g} / \mathrm{kg}$ teve capacidade inibitória significativamente maior que o uso de $5 \mathrm{~g} / \mathrm{kg}$. Esses resultados indicam efeito positivo das folhas de oliveira, uma vez que espécies de Pseudomonas spp. são dominantes em carne de frango deterioradas e estão relacionadas à produção de uma ampla variedade de odores e sabores, devido à ação de suas enzimas lípases e proteases (MELLOR et al., 2011). Pereira et al. (2007) também verificaram efeito positivo do extrato de folhas de oliveira em Pseudomonas.

A carne dos frangos que receberam folhas de oliveira na dieta apresentou número de colônias de aeróbias mesófilas, bactérias láticas, aeróbias psicrotróficas e Pseudomonas significativamente $(p<0,05)$ menor do que o encontrado no tratamento controle. Esses resultados demonstram efeito positivo da oliveira diante de micro-organismos deteriorantes, uma vez que são as bactérias psicrotróficas, e especialmente as Pseudomonas, que deterioram as carcaças de frango durante o período de armazenamento e influenciam a determinação da vida de prateleira dos cortes (MIYAGUSKU et al., 2003). Gök e Bor (2012) também verificaram efeito positivo das folhas de oliveira em aeróbias mesófilas, Pseudomonas e Psicotróficas em almôndegas armazenadas refrigeradas.

A presença de coliformes totais em alimentos, embora menos significativa do que de coliformes termotolerantes, é considerada uma indicação útil de contaminação pós-sanitização ou pós-processo, evidenciando práticas de higiene e sanitização aquém dos padrões requeridos para o processamento de alimento (SILVA et al., 2007). A carne de frango que recebeu dieta suplementada com folhas de oliveira em ambas as concentrações apresentou valores de contagens de coliformes totais significativamente menores que o tratamento controle durante os 12 dias 
Efeito da incorporação de folhas de oliveira (Olea europaea L.) no desenvolvimento e qualidade da carne de frangos MARANGONI, C. et al.

de estocagem. Botsoglou et al. (2010) também obtiveram redução significativa de coliformes totais na carne de peru que recebeu dieta com folhas de oliveira em relação ao controle e Ahmed et al. (2014) obtiveram redução de coliformes totais com o uso de extrato de folhas de oliveira em camarão armazenado refrigerado. Segundo Florentino et al. (1997), a presença de coliformes termotolerantes indica contaminação fecal e presença de bactérias patogênicas. A Resolução n 12/2001, da Agência Nacional de Vigilância Sanitária (BRASIL, 2001),
CTo

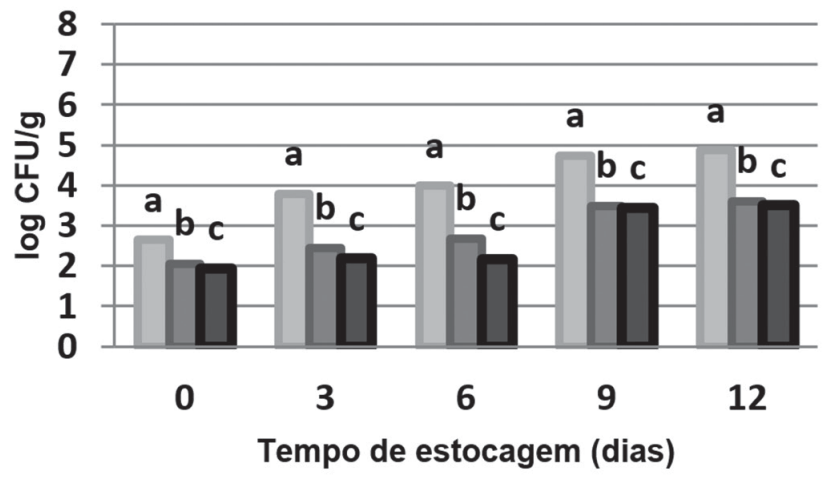

DT1 - Controle DT2 - 5g Oliveira DT3 - $10 \mathrm{~g}$ Oliveira

CCP

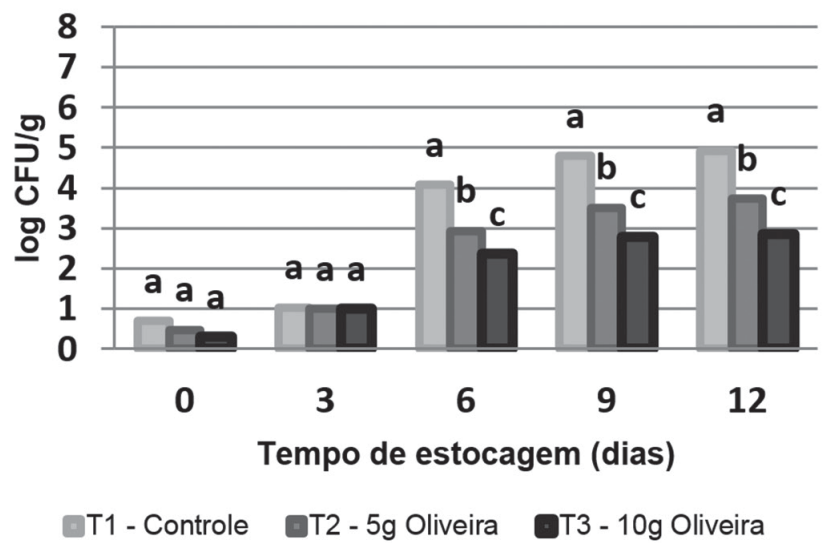

CSA

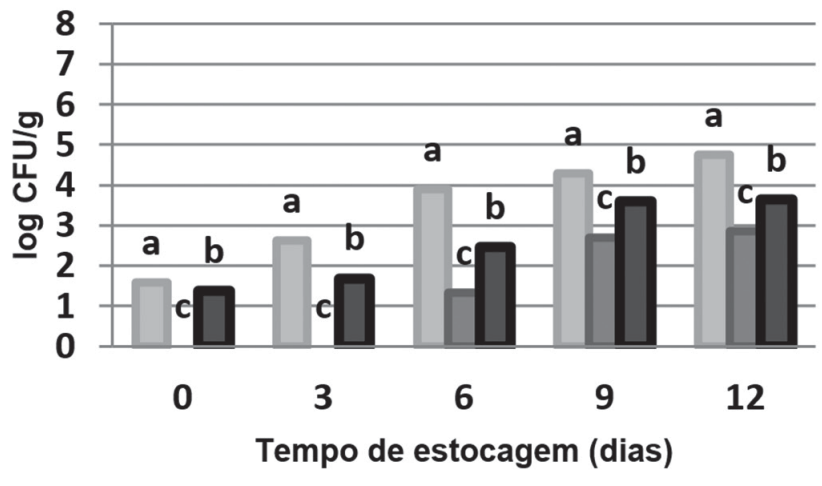

aT1 - Controle DT2 - $5 \mathrm{~g}$ Oliveira DT3 - $10 \mathrm{~g}$ Oliveira
CTE

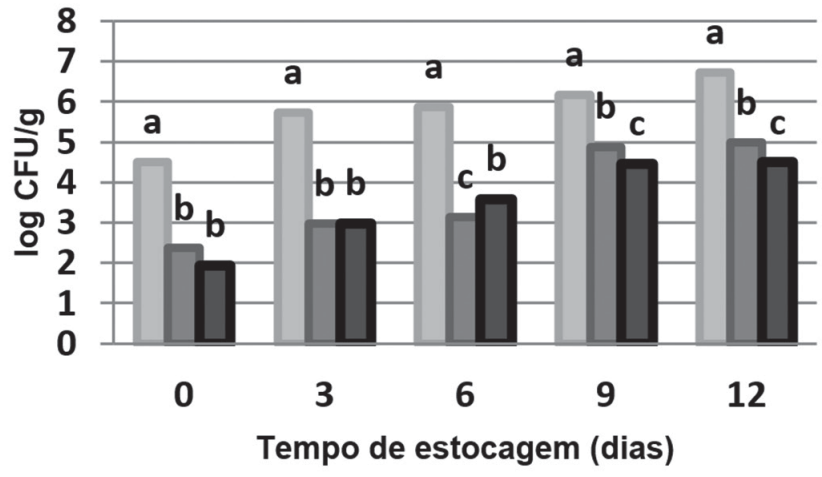

DT1 - Controle DT2 - 5g Oliveira DT3 - $10 \mathrm{~g}$ Oliveira

CE

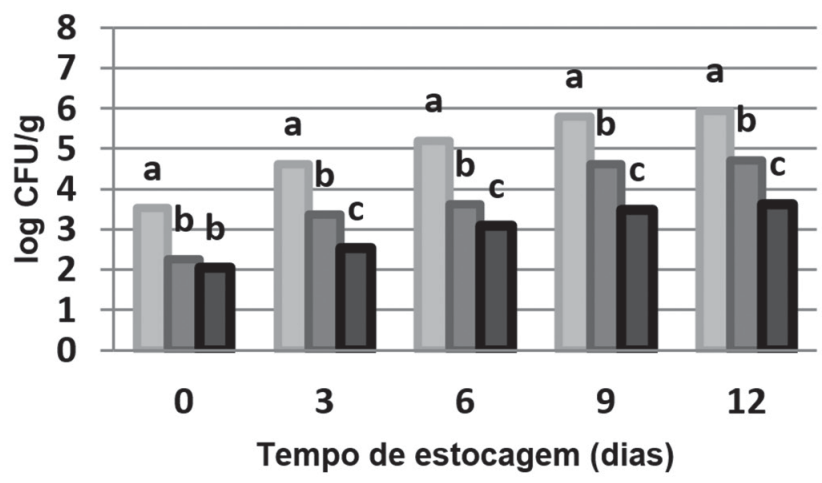

DT1 - Controle DT2 - 5g Oliveira DT3 - $10 \mathrm{~g}$ Oliveira

CEC

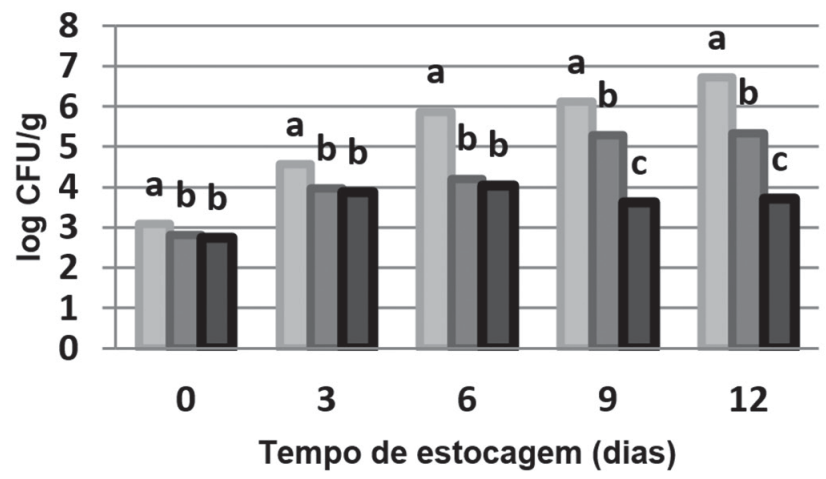

DT1 - Controle DT2 - $5 \mathrm{~g}$ Oliveira DT3 - $10 \mathrm{~g}$ Oliveira

Figura 2. Número de colônias $\left(\log _{10} \mathrm{UFC} / \mathrm{g}\right)$ de Coliformes Totais (CTo); Coliformes Termotolerantes (CTE); Clostridium perfringens (CCP); Enterococcus spp. (CE); Staphylococcus aureus (CSA) e Escherichia coli (CEC) em coxas e sobrecoxas de frangos armazenadas a $4{ }^{\circ} \mathrm{C}$ por 12 dias; a,b,c são analisadas entre T1, T2 e T3 por intervalo de análise. Letras diferentes apresentam diferença significativa $(P<0,05)$ pelo teste de Tukey. 
preconiza para cortes de frango resfriados ou congelados um limite de tolerância para a contagem de Coliformes a $45^{\circ} \mathrm{C} / \mathrm{g}$ de $10^{4}$ ou $4 \log _{10} \mathrm{UFC} / \mathrm{g}$. De acordo com esta tolerância, o tratamento controle estaria impróprio para comercialização e consumo, pois apresentou contagens iniciais de $4,5 \log _{10} \mathrm{UFC} / \mathrm{g}$, enquanto os tratamentos que receberam folhas de oliveira tiveram contagens iniciais de 1,93 e 2,36 para T3 e T2, respectivamente, e apresentaram contagens dentro do limite de tolerância da legislação até o $6^{\circ}$ dia de armazenamento a $4{ }^{\circ} \mathrm{C}$. A análise de Coliformes Termotolerantes indicou que T2 e T3 tiveram efeito inibitório significativo $(p<0,05)$ em relação a $T 1$ durante os 12 dias de armazenamento a $4{ }^{\circ} \mathrm{C}$, demonstrando que ambas as concentrações de oliveira são inibitórias para Coliformes Termotolerantes.

O Clostridium perfringens é uma bactéria gram-positiva que faz parte da microbiota normal do trato intestinal dos animais e é habitante do solo. É causador de processos de intoxicação alimentar pela produção de uma toxina endógena. Em animais saudáveis, encontra-se em maiores porções no cólon (SALES; PORTO, 1999). Al-sheikhly e Truscott (1977) e Benedict (1988) encontraram grande número destes micro-organismos nos pés, penas e pele do pescoço das aves. O uso de folhas de oliveira na quantidade de $10 \mathrm{~g} / \mathrm{kg}$ de ração indicou melhor efeito inibitório que o uso de $5 \mathrm{~g} / \mathrm{kg}$ de ração para Clostridium perfringens, mas ambas as quantidades demonstram capacidade inibitória significativamente $(p<0,05)$ melhor que T1 (Figura 2-CCP).

As coxas e sobrecoxas dos frangos que receberam adição de folhas de oliveira na dieta (T2 e T3) indicaram reduções significativas $(p<0,05)$ nas contagens de Enterococcus spp., demonstrando eficiente redução deste micro-organismo em relação ao tratamento de frangos que recebeu dieta tradicional (T1). A quantidade de $10 \mathrm{~g} / \mathrm{kg}$ teve melhor eficiência que 0 uso de $5 \mathrm{~g} / \mathrm{kg}$, sendo verificados aos 12 dias valores de 3,61, 4,71 e 5,94 $\log _{10}$ UFC/g para T3, T2 e T1, respectivamente. Faiza et al. (2011) avaliaram oliveira em Enterococcus e diversos outros micro-organismos e também verificaram efeito positivo.

Autores relatam que são necessárias entre $10^{5}$ e $10^{6} \mathrm{UFC} / \mathrm{g}$ de Staphylococcus aureus por grama de alimento para que a toxina seja formada em níveis capazes de provocar intoxicação (FRANCO; LANDGRAF, 2005; LINDQVIST et al., 2002). Considerando este padrão e analisando a Figura 2-CSA, pode-se dizer que, durante os 12 dias, as coxas e sobrecoxas dos tratamentos de frango que receberam dieta suplementada com folhas de oliveira apresentaram contagens significativamente menores $(p<0,05)$ que o controle, o que é indicativo de condições mais seguras para o consumo da carne de frango em relação a este micro-organismo. As contagens máximas encontradas para as coxas e sobrecoxas de frango foram de 2,84, 3,64 e 4,74 log CFU/g para T2, T3 e T1, respectivamente. A inibição de Staphylococcus aureus foi significativamente $(p<0,05)$ menor para o tratamento que recebeu adição de $5 \mathrm{~g}$ de oliveira/kg de ração em relação a T1 e T3. Com 12 dias, a diferença entre T3 e T1 foi de $1,1 \log _{10}$ UFC/g, demonstrando efeito inibitório da oliveira em relação ao controle. O efeito positivo das folhas de oliveira para Staphylococcus aureus também foi relatado por Bisignano et al. (1999), Pereira et al. (2007), Botsoglou et al. (2010) e Gökmen et al. (2014).

A presença de Escherichia coli nos alimentos indica contaminação microbiana de origem fecal e condições higiênicas insatisfatórias, sendo diversas linhagens patogênicas (FRANCO; LANDGRAF, 2005). A presença de Escherichia coli (Figura 2-CEC) iniciou com valores próximos entre os três tratamentos 3,07 , 2,79 e 2,73 log CFU/g para T1, T2 e T3, respectivamente, mas com reduções significativas $(p<0,05)$ das contagens nas coxas e sobrecoxas que receberam folhas de oliveira em relação ao controle, demonstrando que o uso de oliveira em ambas as concentrações teve efeito inibitório. Pereira et al. (2007) e Gökmen et al. (2014) também obtiveram efeito positivo do extrato das folhas de oliveira para Escherichia coli.

Não foi evidenciada presença de Salmonella spp. na carne, confirmando a qualidade microbiana dos produtos, pois a ausência atesta condições higiênico-sanitárias satisfatórias (SILVA JUNIOR, 2001).

A Listeria monocytogenes é um patógeno psicrotrófico que pode causar doenças (SCHWAB; EDELWEISS, 2003; FARBER; PETERKIN, 1991; RYSER; MARTH, 1991), pode crescer em temperatura mínima de $1{ }^{\circ} \mathrm{C}$, e desenvolver-se em carne refrigerada (PELISSER et al., 2001; MURIANA, 1996). As coxas e sobrecoxas de frango dos três tratamentos analisados apresentaram ausência de Listeria monocytogenes durante os 12 dias, atestando segurança do produto quanto à listeriose. Gökmen et al. (2014) relataram efeito positivo de extratos de folhas de oliveira para Listeria monocytogenes.

Campylobacter é uma das principais bactérias causadoras de gastrenterite em humanos. Estão presentes naturalmente no trato gastrointestinal de aves e outros animais de produção. Dentre as espécies mais conhecidas estão coli, jejuni e lari (LAWSON et al., 1997). Não foi detectada a presença de nenhuma espécie de campylobacter nos tratamentos armazenados por 12 dias a $4{ }^{\circ} \mathrm{C}$.

A pesquisa de Shigella, Klebsiela, Yersinia e Streptococcus indicou ausência destes micro-organismos para os três tratamentos durante o período avaliado. 
Pereira et al. (2007) relataram que as folhas de oliveira possuem capacidade antimicrobiana na seguinte ordem Bacillus cereus $>$ Candida albicans $>E$. coli>S. aureus $>$ P. aeruginosa. Eles também relataram que o mecanismo antimicrobiano das folhas de oliveira ocorre por meio da desnaturação proteica e da alteração da permeabilidade da membrana celular. Efeito positivo também foi verificado por Lee e Lee (2010), em que uma mistura de compostos fenólicos preparada a partir de folhas de oliveira demonstrou inibição em B. cereus e S. enteritidis. Owen et al. (2003) também relataram que as folhas de oliveira apresentaram atividade antimicrobiana contra E. coli, S. aur'us, B. cereus, S. typhi e V. parahaemolyticus.

$O$ efeito antimicrobiano das folhas de oliveira em diversas bactérias, conforme relatado em estudos realizados (LEE; LEE, 2010; GOVARIS et al., 2010; PEREIRA et al., 2007; CARDOSO et al., 2005; OWEN et al., 2003; BENAVENTE-GARCIA et al., 2000) com relação à atividade antimicrobiana das folhas de oliveira, o que, conforme mencionado por Govaris et al. (2010) e verificados nesta pesquisa, pode ser atribuído à presença de compostos fenólicos como a oleuropeína, que apresenta-se em grande concentração nas folhas de oliveira (TAN et al., 2003). Savournin et al. (2001), relataram que folhas de oliveira podem conter até $10 \%$ de polifenóis, principalmente oleuropeina e hidroxitirosol. Neste estudo, verificou-se a presença de 15\% de oleuropeina nas folhas de oliveira, o que pode justificar o menor crescimento microbiano na carne dos frangos que receberam folhas de oliveira na dieta. Os compostos fenólicos das folhas de oliveira são os principais responsáveis pela sua ação bactericida/bacteriostática. A ação destes compostos é, sobretudo, exercida ao nível da membrana celular da bactéria, provocando danos estruturais e funcionais. As substâncias ativas das plantas são capazes de alterar a estrutura fosfolipídica da membrana celular, interrompendo o sistema enzimático, comprometendo o material genético da bactéria e formando compostos tóxicos, como o peróxido de hidrogênio (AFONSO, 2014; CIRQUEIRA, 2010). A ação positiva das folhas de oliveira in vivo também foi verificada em filés de peru (BOTSOGLOU et al., 2010) e em carne suína (PAIVA-MARTINS et al., 2013; BOTSOGLOU et al., 2012; PAIVA-MARTINS et al., 2009) e, em todas as pesquisas, o efeito positivo diante das bactérias foi atribuído à presença de compostos fenólicos e à oleuropeína, o que, conforme mencionado por Govaris et al. (2010), recomenda o uso de folhas de oliveira como suplemento nutricional ou componente funcional de alimentos, ou Gökmen et al. (2014) que indicam o uso de folhas de oliveira pela indústria de alimentos como um antimicrobiano natural.

\section{Conclusão}

A utilização de $10 \mathrm{~g} / \mathrm{kg}$ de folhas de oliveira proporcionou menor taxa de mortalidade e o uso de $5 \mathrm{~g} / \mathrm{kg}$ apresentou melhor conversão alimentar nos frangos. A incorporação de folhas de oliveira em ambas as quantidades inibiu o crescimento microbiano nas coxas e sobrecoxas armazenadas a $4^{\circ} \mathrm{C}$ durante 12 dias. O uso de $10 \mathrm{~g} / \mathrm{kg}$ demonstrou melhor capacidade inibitória para Enterococcus spp., Bactérias ácido láticas, Pseudomonas, Clostridium perfringens, Escherichia coli, Coliformes termotolerantes e fecais, enquanto a inibição de Staphylococcus aureus, aeróbios psicrotróficos e mesófilos foi mais eficiente quando se utilizou $5 \mathrm{~g} / \mathrm{kg}$.

\section{Referências}

AFONSO, S. M. Utilização de extratos de folhas de oliveira como agente antioxidante. 2014. 90 p. Dissertação (Mestrado em Qualidade e Segurança Alimentar)-Instituto Politécnico de Bragança, Bragança, 2014.

AHMED, A. M.; RABII, N. S.; GARBAJ, A. M.; ABOLGHAIT, S. K. Antibacterial effect of olive (Olea europaea L.) leaves extract in raw peeled undeveined shrimp (Penaeus semisulcatus). International Journal of Veterinary Science and Medicine, Giza, v. 2, n. 1, p. 53-56, 2014. http://dx.doi.org/10.1016/j. ijvsm.2014.04.002.

ALLEN, C. D.; RUSSELL, S. M.; FLETCHER, D. L. The relationship of broiler breast meat color and $\mathrm{pH}$ to shelf life and odor development. Poultry Science, Champaign, v. 76, n. 7 , p. 1042-1046, 1997. http://dx.doi.org/10.1093/ps/76.7.1042. PMid:9200242.

AL-SHEIKHLY, F.; TRUSCOTT, R. B. The pathology of necrotic enteritis of chickens following infusion of broth cultures of Clostridium perfringens into the duodenum. Avian Diseases, Kennett Square, v. 21, p. 230-240, 1977.

BENAVENTE-GARCIA, O.; CASTILLO, J.; LORENTE, J.; ORTUNO, A.; DEL RIO, J. A. Antioxidant activity of phenolics extracted from Olea europaea L. leaves. Food Chemistry, London, v. 68, n. 4, p. 457-462, 2000. http://dx.doi.org/10.1016/ S0308-8146(99)00221-6.

BENEDICT, R. C. Microbial attachment to meat surfaces. In: ANNUAL RECIPROCAL MEAT CONFERENCE, 41., 1995, San Antonio. Proceedings... Champaign: American Meat Science Association, 1988. v. 41, p. 1-6.

BISIGNANO, G.; LAGANA, M. G.; TROMBETTA, D.; ARENA, S.; NOSTRO, A.; UCCELLA, N.; MAZZANTI, G.; SAIJA, A. In vitro antibacterial activity of some aliphatic aldehydes from Olea europea L. FEMS Microbiology Letters, Amsterdam, v. 198, n. 1, p. 9-13, 2001. http://dx.doi.org/10.1111/j.1574-6968.2001. tb10611.x. PMid:11325546.

BISIGNANO, G.; TOMAINO, A.; LO CASCIO, R.; CRISAFI, G.; UCCELLA, N.; SAIJA, A. On the 'in vitro' antimicrobial activity of 
Efeito da incorporação de folhas de oliveira (Olea europaea L.) no desenvolvimento e qualidade da carne de frangos MARANGONI, C. et al.

oleuropein and hydroxytyrosol. The Journal of Pharmacy and Pharmacology, Italy, v. 51, n. 8, p. 971-974, 1999. http://dx.doi. org/10.1211/0022357991773258. PMid:10504039.

BOCK, M.; DERRAIK, J.; BRENNAN, C.; BIGGS, J.; MORGAN, P.; HODGKINSON, S.; HOFMAN, P.; CUTFIELD, W. Olive (Olea europaea L.) leaf polyphenols improve insulin sensitivity in middle-aged overweight men: a randomized, placebocontrolled, crossover trial. PLoS One, San Francisco, v. 8, n. 3, p. e57622, 2013. http://dx.doi.org/10.1371/journal.pone.0057622. PMid:23516412.

BOTSOGLOU, E.; GOVARIS, A.; AMBROSIADIS, I.; FLETOURIS, D. Lipid and protein oxidation of -linolenic acid-enriched pork during refrigerated storage as influenced by diet supplementation with olive leaves (Olea Europea L.) or -tocopheryl acetate. Meat Science, Barking, v. 92, n. 4, p. 525-532, 2012. http://dx.doi. org/10.1016/j.meatsci.2012.05.022. PMid:22710099.

BOTSOGLOU, E.; GOVARIS, A.; CHRISTAKI, E.; BOTSOGLOU, $N$. Effect of dietary olive leaves and/or a-tocopheryl acetate supplementation on microbial growth and lipid oxidation of turkey breast fillets during refrigerated storage. Food Chemistry, London, v. 121, n. 1, p. 17-22, 2010. http://dx.doi.org/10.1016/j. foodchem.2009.11.083.

BRASIL. Ministério da Agricultura, Pecuária e Abastecimento. Instrução Normativa n²0, de 21 de julho de 1999. Métodos analíticos físico-químicos para controle de produtos cárneos e seus ingredientes: sal e salmoura. Diário Oficial [da] República Federativa do Brasil, Brasília, DF, 9 set. 1999. Seção 1.

BRASIL. Ministério da Agricultura, Pecuária e Abastecimento. Instrução Normativa $n^{\circ} 12$, de 10 de abril de 2001. Metodologias analíticas, ingestão diária admissível e limites máximos de resíduos para medicamentos veterinários em alimentos de origem anima. Diário Oficial [da] República Federativa do Brasil, Brasília, DF, 12 abr. 2001. Seção 1.

BRASIL. Ministério da Agricultura, Pecuária e Abastecimento. Instrução Normativa n62, de 26 de agosto de 2003. Manual de métodos analíticos oficiais para análises microbiológicas para controle de produtos de origem animal e água. Diário Oficial [da] República Federativa do Brasil, Brasília, DF, 18 set. 2003. Seção 1, p. 14, Capítulo II.

CARDOSO, S. M.; GUYOT, S.; MARNET, N.; LOPES-DA-SILVA, J. A.; RENARD, C. M. G. C.; COIMBRA, M. A. Characterization of phenolic extracts from olive pulp and olive pomace by electrospray mass spectrometry. Journal of the Science of Food and Agriculture, London, v. 85, n. 1, p. 21-32, 2005. http:// dx.doi.org/10.1002/jsfa. 1925.

CAYAN, H.; ERENER, G. Effect of olive leaf (Olea europaea) powder on laying hens performance, egg quality and egg yolk cholesterol levels. Asian-Australasian Journal of Animal Sciences, Seoul, v. 28, n. 4, p. 538-543, 2015. http://dx.doi. org/10.5713/ajas.14.0369. PMid:25656181.
CHRISTAKI, E. V.; BONOS, E. M.; FLOROU-PANERI, P. C. Comparative evaluation of dietary oregano, anise and olive leaves in laying Japanese quails. Revista Brasileira de Ciencia Avicola $=$ Brazilian Journal of Poultry Science, Campinas, $\mathrm{v}$. 13, p. 97-101, 2011.

CIRQUEIRA, M. Agentes antimicrobianos químicos e naturais. Food Ingredients Brasil, São Paulo, n. 15, p. 36-42, 2010.

DELAZARI, I. Programas de segurança de alimentos na indústria de produtos avícolas. In: CONFERÊNCIA APINCO DE CIÊNCIA E TECNOLOGIA AVÍCOLAS, 2003, Campinas. Anais... Campinas: FACTA, 2003. p. 123-126.

DOMINGUEZ, S. A.; SCHAFFNER, D. W. Development and validation of a mathematical model to describe the growth of Pseudomonas spp. in raw poultry stored under aerobic conditions. International Journal of Food Microbiology, Amsterdam, v. 120, n. 3, p. 287-295, 2007. http://dx.doi. org/10.1016/j.ijfoodmicro.2007.09.005. PMid:17949841.

ERENER, G.; OCAK, N.; OZTURK, E.; CANKAYA, S.; OZKANCA. $R$. The effects of olive leaf extract on performance, some blood parameters and cecal microflora of broilers. Ankara: The Scientific and Technological Research Council of Turkey, 2009. AFVRG-Project No: 1070820 report of final results.

FAIZA, I.; WAHIBA, K.; NASSIRA, G.; CHAHRAZED, B.; ATIK, B. F. Antibacterial and antifungal activities of olive (Olea europaea L.) from Algeria. Journal of Microbiology and Biotechnology Research, Algeria, v. 1, p. 69-73, 2011.

FARBER, J. M.; PETERKIN, P. I. Listeria monocytogenes, a food borne pathogen. Microbiological Reviews, Washington, v. 55, n. 3, p. 476-511, 1991. PMid:1943998.

FLORENTINO, E. R.; LEITE, J. F.; AS, S. N. Avaliação da qualidade microbiológica da carne comercializada em Campina Grande-PB. Revista Higiene Alimentar, São Paulo, v. 11, n. 47, p. 56-68, 1997.

FRANCO, B. D. G. M.; LANDGRAF, M. Microbiologia dos alimentos. São Paulo: Atheneu, 2005. 182 p.

GILL, C. O. Microbiological contamination of meat during slaughter and butchering of cattle, sheep and pigs. In: DAVIES, A.; BOARD, R. (Eds.). Microbiology of meat and poultry. London: Blackie Academic and Professional, 1998. p. 118-157.

GÖK, V.; BOR, Y. Effect of olive leaf, blueberry and Zizyphus jujuba extracts on the quality and shelf life of meatball during storage. Journal of Food Agriculture and Environment, Helsinki, v. 10, p. 190-195, 2012.

GÖKMEN, M.; KARA, R.; AKKAYA, L.; TORLAK, E.; ÖNEN, A. Akkaya, I.; Torlak, E.; Önen, A. Evaluation of antimicrobial activity in olive (Olea europaea) leaf extract. American Journal of Microbiology, Turkey, v. 5, n. 2, p. 37-40, 2014. http://dx.doi. org/10.3844/ajmsp.2014.37.40. 
Efeito da incorporação de folhas de oliveira (Olea europaea L.) no desenvolvimento e qualidade da carne de frangos MARANGONI, C. et al.

GOVARIS, A.; BOTSOGLOU, E.; MOULAS, A.; BOTSOGLOU, $N$. Effect of dietary olive leaves and Rosemary on microbial growth and lipid oxidation of turkey breast during refrigerated storage. South African Journal of Animal Science, v. 40, n. 2 , p. 145-155, 2010. http://dx.doi.org/10.4314/sajas.v40i2.57287.

HORWITZ, W. (Ed.). Official methods of analysis of Association of Oficial Analytical Chemists. 18th ed. Gaithersburg: AOAC, 2003.

INTERNATIONAL COMMISSION ON MICROBIOLOGICAL SPECIFICATIONS FOR FOODS - ICMSF. Microorganisms in foods: sampling for microbiological analysis: principles and scientific applications. Toronto: University of Toronto, 1986. v. 2, p. 181-186.

INTERNATIONAL ORGANIZATION FOR STANDARDIZATION ISO. ISO 13720: meat and meat products: enumeration of presumptive Pseudomonas spp. Geneva: ISO, 2010.

JAY, J. M. Microbiologia de alimentos. 6. ed. Porto Alegre: Artmed, 2005.

KOMAKI, E.; YAMAGUCHI, S.; MARU, I.; KINOSHITA, M.; KAKEHI, K.; OHTA, Y.; TSUKADA, Y. Identification of anti-. ALPHA.-amylase components from olive leaf extracts. Food Science and Technology Research, Japan, v. 9, n. 1, p. 35-39, 2003. http://dx.doi.org/10.3136/fstr.9.35.

KONTOGIANNI, V.; GEROTHANASSIS, I. Phenolic compounds and antioxidante activity of olive leaf extracts. Natural Product Research, Portugal, v. 26, n. 2, p. 186-189, 2012. http://dx.doi. org/10.1080/14786419.2011.582842. PMid:22060136.

LAWSON, A. J.; LINTON, D.; STANLEY, R. J.; OWEN, R. $\mathrm{J}$. Polymerase chain reaction detection and speciation of Campylobacter upsaliensis and C. helveticus in human faeces and comparison with culture techniques. Journal of Applied Microbiology, Oxford, v. 83, n. 3, p. 375-380, 1997. http://dx.doi. org/10.1046/j.1365-2672.1997.00240.x. PMid:9351218.

LEE, O. H.; LEE, B. Y. Antioxidant and antimicrobial activities of individual and combined Phenolics in Olea europea leaf extract. Bioresource Technology, Essex, v. 101, n. 10, p. 37513754, 2010. http://dx.doi.org/10.1016/j.biortech.2009.12.052. PMid:20106659

LEE-HUANG, S.; ZHANG, L.; LIN HUANG, P.; CHANG, Y.; HUANG, P. Anti-HIV activity of olive leaf extract (OLE) and modulation of host cell gene expression. By HIV-1 infection and OLE treatment. Biochemical and Biophysical Research Communications, Orlando, v. 307, n. 4, p. 1029-1037, 2003. http://dx.doi.org/10.1016/S0006-291X(03)01292-0. PMid:12878215.

LINDQVIST, R.; SYLVÉN, S.; VAGSHOLM, I. Quantitative microbial risk assessment exemplified by Staphylococcus aureus in unripened cheese made from raw milk. International Journal of Food Microbiology, Amsterdam, v. 78, n. 1-2, p. 155-170,
2002. http://dx.doi.org/10.1016/S0168-1605(02)00237-4. PMid:12222631.

MALIK, N. S. A.; BRADFORD, J. M. Recovery and stability of oleuropein and other phenolic compounds during extraction and processing of olive (Olea europaea L.) leaves. Journal of Food Agriculture and Environment, Helsinki, v. 6, p. 8-13, 2008.

MARKIN, D.; DUEK, L.; BERDICEVSKY, I. In vitro antimicrobial activity of olive leaves. Mycoses, Berlin, v. 46, n. 3-4, p. 132-136, 2003. http://dx.doi.org/10.1046/j.1439-0507.2003.00859.x. PMid:12870202.

MEHYAR, G. Effectiveness of trisodium phosphate, lactic acid and commercial antimicrobials against pathogenic bacteria on chicken skin. Food Protection Trends, Des Moines, v. 25, p. 351-362, 2005.

MELLOR, G. E.; BENTLEY, J. A.; DYKES, G. A. Evidence for a role of biosurfactants produced by Pseudomonas fluorescens in the spoilage of fresh aerobically stored chicken meat. Food Microbiology, London, v. 28, n. 5, p. 1101-1104, 2011. http:// dx.doi.org/10.1016/j.fm.2011.02.003. PMid:21569958.

MIYAGUSKU, L.; CHEN, F.; LEITÃO, M. F. F.; BAFFA, O. Microbiological and sensory evaluation of the shelf-life of irradiated chicken breast meat. Ciência e Tecnologia de Alimentos, Campinas, v. 23, p. 7-16, 2003. http://dx.doi. org/10.1590/S0101-20612003000400003.

MURIANA, P. M. Bacteriocins for control of Listeria spp. in food. Journal of Food Protection, Des Moines, v. 59, p. 54-63, 1996.

NASCIMENTO, F. C. A. Aspectos socioeconômicos das doenças veiculadas pelos alimentos. 2011. Disponível em: <http://www.nutricaoempauta.com.br/lista_artigo. php?cod=127>. Acesso em: 10 ago. 2011.

NASCIMENTO, G. M. Utilização de produtos alternativos aos antibióticos moduladores de crescimento na produção de frango de corte. 2013. 33 f. Tese (Doutorado em Ciência Animal)-Universidade Federal de Goiás, Goiânia, 2013.

OLIVEIRA, A. L.; PEREIRA, M. T.; BUENO, P. H. S.; OLIVEIRA, R. B. P.; PINTO, F. C.; CORREIA, R. F.; MACHADO, M. M. Qualidade microbiológica da carne de frango irradiada em embalagem convencional e a vácuo. Arquivo Brasileiro de Medicina Veterinária e Zootecnia, Belo Horizonte, v. 61, n. 5, p. 1210-1217, 2009. http://dx.doi.org/10.1590/S010209352009000500026.

OLIVEIRA, W. F.; CARDOSO, W. M.; MARQUES, L. C. L.; SALLES, R. P. R.; AGUIAR FILHO, J. L. C.; TEIXEIRA, R. S. C. T.; ROMÃO, J. M.; LIMA, A. C. P. Use of diferente culture medias to enterobacteria isolation in feces samples from industrial broiler flocks in Ceará state, Brasil. Revista Portuguesa de Ciências Veterinárias, Lisboa, v. 99, p. 211-214, 2004.

OWEN, R. W.; HAUBNER, R.; MIER, W.; GIACOSA, A.; HULL, W. E.; SPIEGELHALDER, B.; BARTSCH, H. Isolation, structure elucidation and antioxidant potential of the major phenolic 
Efeito da incorporação de folhas de oliveira (Olea europaea L.) no desenvolvimento e qualidade da carne de frangos MARANGONI, C. et al.

and flavonoid compounds in brined olive drupes. Food and Chemical Toxicology, Amsterdam, v. 41, n. 5, p. 703-717, 2003. http://dx.doi.org/10.1016/S0278-6915(03)00011-5. PMid:12659724

PAIVA-MARTINS, F.; BARBOSA, S.; PINHEIRO, V.; MOURÃO, J. L.; OUTOR-MONTEIRO, D. The effect of olive leaves supplementation on the feed digestibility, growth performances of pigs and quality of pork meat. Meat Science, Barking, v. 82, n. 4, p. 438-443, 2009. http://dx.doi.org/10.1016/j. meatsci.2009.02.014. PMid:20416688.

PAIVA-MARTINS, F.; RIBEIRINHA, T.; SILVA, A.; GONÇALVES, R.; PINHEIRO, V.; MOURÃO, J. L.; OUTOR-MONTEIRO, D. Effects of the dietary incorporation of olive leaves on growth performance, digestibility, blood parameters and meat quality of growing pigs. Society of Chemical Industry, London, v. 94, p. 3023-3029, 2013.

PELISSER, M. R.; MENDES, S. D. C.; SUTHERLAND, A. D.; BATISTA, C. R. V. Detection of Listeria species in refrigerated chicken carcasses using Clearview TM and a modified conventional culture method. Brazilian Journal of Microbiology, São Paulo, v. 32, n. 2, p. 113-116, 2001. http:// dx.doi.org/10.1590/S1517-83822001000200008.

PEREIRA, A. P.; FERREIRA, I. C. F. R.; MARCELINO, F.; VALENTÃO, P.; ANDRADE, P. B.; SEABRA, R.; ESTEVINHO, L.; BENTO, A.; PEREIRA, J. A. Phenolic Compounds and Antimicrobial Activity of Olive (Olea europaea L. CV. Corbançosa) Leaves. Molecules, Basel, v. 12, n. 5, p. 1153-1162, 2007. http:// dx.doi.org/10.3390/12051153. PMid:17873849.

RITTER, R.; BERGMANN, G. P. Eficácia do sistema de pré-resfriamento de frangos em tanques, sobre a redução da contaminação bacteriana de carcaças. Higiene alimentar, São Paulo, v. 17, p. 97-104, 2003

RUIZ-BARBA, J. L.; RIOS-SANCHEZ, R. M.; FEDRIANI-IRISO, C.; OLIAS, J. M.; RIOS, J. L.; JIMENEZ-DIAZ, R. Bactericidal effect of phenolic compounds from green olive against $L$. plantarum. Systematic and Applied Microbiology, Stuttgart, v. 13, n. 2, p. 199-205, 1990. http://dx.doi.org/10.1016/S07232020(11)80170-0.

RYSER, E. T.; MARTH, E. H. Listeria, listeriosis, and food safety. New York: University of Wisconsin, 1991. 632 p.
SALES, R. O.; PORTO, E. Disseminação bacteriana. Principais patógenos e higienização no abate de frangos: uma revisão. Revista Científica de Produção Animal, Teresina, v. 1, p. 211-226, 1999.

SALFINGER, Y.; TORTORELLO, M. L. (Ed.). Compendium of methods for the microbiological examination of foods. 4th ed. Washington: American Public Health Association, 2001.

SAVOURNIN, C.; BAGHDIKIAN, B.; ELIAS, R.; DARGOUTHKESRAOUI, F.; BOUKEF, K.; BALANSARD, G. Rapid high-performance liquid chromatography analysis for the quantitative determination of oleuropein in Olea europaea leaves. Journal of Agricultural and Food Chemistry, Easton, v. 49, p. 618-621, 2001.

SCHWAB, J. P.; EDELWEISS, M. I. A. Identificação imunohistoquímica de Listeria monocytogenes em placentas fixadas em formol e embebidas em parafina. Revista Brasileira de Ginecologia e Obstetrícia, Rio de Janeiro, v. 25, n. 7, p. 501-505, 2003.

SILVA JUNIOR, E. A. S. Manual de controle higiênico sanitário em alimentos. 4. ed. São Paulo: Varela, 2001. 475 p.

SILVA, N.; JUNQUEIRA, V. C. A.; SILVEIRA, N. F. A.; TANIWAKI, M. H.; SANTOS, R. F. S.; GOMES, R. A. R. Manual de métodos de análise microbiológica de alimentos. 3. ed. São Paulo: Varela, 2007

SUDJANA, A. N.; D'ORAZIO, C.; RYAN, V.; RASOOL, N.; NG, J.; ISLAM, N.; RILEY, T. V.; HAMMER, K. A. Antimicrobial activity of commercial Olea europaea (olive) leaf extract. International Journal of Antimicrobial Agents, Australia, v. 33, n. 5, p. 461-463, 2009. http://dx.doi.org/10.1016/j. ijantimicag.2008.10.026. PMid:19135874.

TAN, C. P.; CHE MAN, Y. B.; JINAP, S.; YUSOFF, M. S. A. Effects of microwave heating on changes in chemical and thermal properties of vegetable oils. Journal of the American Oil Chemists Society, Chicago, v. 78, p. 1227-1232, 2003.

UNIÃO BRASILEIRA DE AVICULTURA - UBABEF. Annual report: 2012. São Paulo: UBABEF, 2012.

VILLA, F.; OLIVEIRA, A. F. Origem e expansão da oliveira na América Latina. In: OLIVEIRA, A. F. Oliveira no Brasil: tecnologias de produção. Belo Horizonte: EPAMIG, 2012. cap. 1, p. 21-28. 